\title{
Concentrations of Hazardous Heavy Metals in Environmental Samples Collected in Xiamen, China, as Determined by Vapor Generation Non-dispersive Atomic Fluorescence Spectrometry
}

\author{
Jing Liang, Qiuquan WANG, ${ }^{\dagger}$ and Benli HuANG \\ Department of Chemistry \& the MOE Key Laboratory of Analytical Science, Xiamen University, \\ Xiamen 361005, China
}

\begin{abstract}
Non-dispersive atomic fluorescence spectrometry (NDAFS) coupled with vapor generation (VG) sample introduction was applied to the determination of the concentrations of hazardous heavy metals, such as arsenic, cadmium, lead and mercury, in seawater, soils and total airborne particulate matter (PM) collected around the Xiamen area in China. Almost $100 \%$ sample introduction efficiency was achieved by using thiourea and ascorbic acid for the pre-reduction of $\mathrm{As}^{\mathrm{V}}$ to $\mathrm{As}^{\mathrm{III}}, \mathrm{K}_{3} \mathrm{Fe}(\mathrm{CN})_{6}$ and tartaric acid for pre-oxidation of $\mathrm{Pb}^{\mathrm{II}}$ to $\mathrm{Pb}^{\mathrm{IV}}$, and masking the interferences arising from the coexisting transition metals to $\mathrm{As}, \mathrm{Cd}, \mathrm{Hg}$ and $\mathrm{Pb}$ during their vapor generation process. Moreover, a novel sample pretreatment device was developed to avoid the loss of mercury, lead, cadmium and arsenic during sample pretreatment. With such methods, the detection limit (DL) of arsenic, cadmium, lead and mercury was down to $0.08,0.03,0.05,0.01 \mathrm{ng}$ $\mathrm{mL}^{-1}(3 \sigma)$, respectively. The relative standard deviations (RSD, $n=11$ ) for arsenic, cadmium, lead and mercury at $10 \mathrm{ng}$ $\mathrm{mL}^{-1}$ were $0.9 \%, 1.6 \%, 1.3 \%$ and $2.0 \%$, respectively. The concentrations of hazardous heavy metals in the environmental samples collected in Xiamen, China are in the range from $0.02 \pm 0.001 \mathrm{ng} \mathrm{mL}^{-1}$ in seawater to $15.3 \pm 0.2 \mu \mathrm{g} \mathrm{g}^{-1}$ in soils. Besides flame/GF-AAS and ICP-AES/MS, VG-NDAFS should be another choice for the determination of hazardous heavy metals in environmental samples.
\end{abstract}

(Received September 30, 2003; Accepted November 18, 2003)

\section{Introduction}

The toxicity of hazardous heavy metals, such as arsenic, cadmium, lead and mercury, has been well recognized for a long time. Along with the widespread application of hazardous heavy metals in various fields of our life, they have been inherently emitted into the environments around us. Since the potential risk and environmental damage of them have been well documented in many publications, they have often been considered to be a so-called "Chemical Time Bomb". ${ }^{1}$ In order to prevent and remediate our environment from the pollution of hazardous heavy metals, information about the concentrations of hazardous heavy metals in the environment is absolutely necessary. Even with the very good performance of atomic absorption spectrometry (AAS), ${ }^{2-5}$ inductively coupled plasma atomic emission spectrometry (ICP-AES) ${ }^{6}$ and mass spectrometry (ICP-MS) ${ }^{7-11}$ as well as high-performance liquid chromatography (HPLC) $)^{12-14}$ for the determination of hazardous heavy metals in environmental samples, the interferences arising from matrices and spectra are still inevitable, and sometimes very serious. Conventional quadrupole ICP-MS has a low detection limit (DL), and spectral interferences are greatly reduced because $\mathrm{m} / \mathrm{z}$ signals are detected, but interferences from polyatomic ion species still exist, especially for ${ }^{75} \mathrm{As}^{+}$from the interference of ${ }^{40} \mathrm{Ar}^{35} \mathrm{Cl}^{+}$; moreover, because the quadrupole

$\dagger$ To whom correspondence should be addressed.

E-mail: qqwang@jingxian.xmu.edu.cn surface in the mass analyzer is usually modified by gold, it is not strongly recommended to be used when $\mathrm{Hg}$ is contained in the samples due to the formation of a gold amalgam. Atomic fluorescence spectrometry (AFS) $)^{15-17}$ coupled with vapor generation (VG) of arsenic $^{18}$ and lead, ${ }^{18}$ mercury ${ }^{19}$ and cadmium, ${ }^{20,21}$ which has been proved to be a high-efficiency sample introduction technique, ${ }^{22}$ provides a promising ability in the determination of hazardous heavy metals. The DLs of the non-dispersive AFS coupled VG technique for the determination of $\mathrm{As}, \mathrm{Cd}, \mathrm{Pb}$ and $\mathrm{Hg}$ is comparable to those of GF-AAS and ICP-MS. A comparison of such DLs is listed in Table 1.

Because of the simplicity of the atomic fluorescence spectrum and short wavelength of the resonance fluorescence lines of As, $\mathrm{Cd}, \mathrm{Pb}$ and $\mathrm{Hg}(<300 \mathrm{~nm})$, the light dispersive system was omitted when instrumentation was done, and a photomultiplier tube (PMT), which only responds to the light shorter than 350 $\mathrm{nm}$, was equipped in this study. Such a simple non-dispersive atomic fluorescence spectrometer (NDAFS), in which hollowcathode lamps (HCLs) were used as the exciting sources and the $\mathrm{Ar}-\mathrm{H}_{2}$ flame as an atomizer, coupled with an intermittent flow vapor generation sample introduction was developed and applied to the determination of trace $\mathrm{As}, \mathrm{Cd}, \mathrm{Pb}$ and $\mathrm{Hg}$ in environmental samples, such as seawater, soils and total PMs collected from the Xiamen area in China. In addtion, a novel improvement of a sample pretreatment device was also made to avoid the losses of $\mathrm{As}, \mathrm{Cd}, \mathrm{Pb}$ and $\mathrm{Hg}$ during sample digestion. 
Table 1 Comparison of the detection limits $\left(\mathrm{ng} \mathrm{mL}^{-1}\right)$ of hazardous heavy metals obtained by VG-NDAFS and other methods

\begin{tabular}{lcccc}
\hline & VG-NDAFS $^{\mathrm{a}}$ & GF-AAS $^{23}$ & ICP-AES $^{23}$ & ICP-MS $^{23}$ \\
\hline $\mathrm{As}$ & 0.08 & 0.16 & 2 & 0.031 \\
$\mathrm{Cd}$ & 0.03 & 0.004 & 0.07 & 0.005 \\
$\mathrm{~Pb}$ & 0.05 & 0.08 & 1 & 0.01 \\
$\mathrm{Hg}$ & 0.01 & 0.8 & 1 & 0.018 \\
\hline
\end{tabular}

a. Results of this study.

Table 2 Experimental conditions of VG-NDAFS

\begin{tabular}{|c|c|c|c|c|}
\hline & As & $\mathrm{Cd}$ & $\mathrm{Pb}$ & $\mathrm{Hg}$ \\
\hline $\begin{array}{l}\text { Resonance } \\
\text { wavelength (nm) }\end{array}$ & 193.7 & 228.8 & 283.3 & 253.7 \\
\hline $\begin{array}{l}\text { Current of HCL } \\
(\mathrm{mA})\end{array}$ & 60 & 80 & 80 & 30 \\
\hline PMT voltage (V) & -300 & -300 & -300 & -280 \\
\hline Read out mode & Peak area & Peak area & Peak area & Peak area \\
\hline $\mathrm{HCl}(\mathrm{v} / \mathrm{v}, \%)$ & $2^{a}$ & $2^{\mathrm{a}}$ & $3^{\mathrm{b}}$ & $2^{\mathrm{a}}$ \\
\hline $\begin{array}{l}\mathrm{KBH}_{4}(\mathrm{w} / \mathrm{v}, 0.5 \% \\
\mathrm{NaOH})\end{array}$ & 2 & 2 & 2 & 1 \\
\hline $\begin{array}{l}\text { Carrier gas flow } \\
\text { rate }\left(\mathrm{mL} \mathrm{min}^{-1}\right)\end{array}$ & 300 & 300 & 300 & 300 \\
\hline 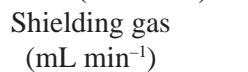 & 1000 & 1000 & 1000 & 1000 \\
\hline $\begin{array}{l}\text { Temperature of } \\
\text { atomizer }\left({ }^{\circ} \mathrm{C}\right)\end{array}$ & 200 & 200 & 200 & 25 \\
\hline $\begin{array}{l}\text { Height of atomizer } \\
(\mathrm{mm})\end{array}$ & 8 & 8 & 8 & 8 \\
\hline
\end{tabular}

a. $2 \% \mathrm{HCl}+5 \%$ thiourea $+5 \%$ ascorbic acid.

b. $3 \% \mathrm{HCl}+2 \% \mathrm{~K}_{3} \mathrm{Fe}(\mathrm{CN})_{6}+0.5 \%$ tartaric acid.

\section{Experimental}

\section{Reagents}

An arsenic stock solution of $1.00 \mathrm{mg} \mathrm{mL}^{-1}$ was prepared by dissolving $1.3203 \mathrm{~g}$ of $\mathrm{As}_{2} \mathrm{O}_{3}$ (purity $\geq 99.99 \%$; Sigma) in 25 $\mathrm{mL}$ of $20 \%(\mathrm{w} / \mathrm{v}) \mathrm{KOH}$ solution, and diluting with $20 \%$ (v/v) $\mathrm{H}_{2} \mathrm{SO}_{4}$ to $1000 \mathrm{~mL}$. Stock solutions of cadmium and lead were prepared by respectively dissolving $1.0000 \mathrm{~g}$ of cadmium and lead (purity $\geq 99.99 \%$; Shanghai Chemicals, China) in $10 \mathrm{~mL}$ of $\mathrm{HNO}_{3}(1: 1, \mathrm{v} / \mathrm{v})$, and diluting with Milli-Q water so as to give a concentration of $1.00 \mathrm{mg} \mathrm{mL}^{-1}$. A mercury stock solution of $1.00 \mathrm{mg} \mathrm{mL}^{-1}$ was prepared by dissolving $1.6631 \mathrm{~g}$ of $\mathrm{Hg}\left(\mathrm{NO}_{3}\right)_{2}$ (purity $\geq 99.99 \%$; Shanghai Chemicals) in $20 \mathrm{~mL}$ of $\mathrm{HNO}_{3}(1: 3$, $\mathrm{v} / \mathrm{v})$, and diluting with water to $1000 \mathrm{~mL}$. Potassium tetrahydroborate $\left(\mathrm{KBH}_{4}\right.$; Shanghai Chemicals) in a $0.5 \%(\mathrm{w} / \mathrm{v})$ $\mathrm{NaOH}$ solution was daily prepared and filtered through a 0.45 $\mu \mathrm{m}$ membrane filter before use. The glassware and plastic bottles were soaked in $10 \%(\mathrm{v} / \mathrm{v})$ nitric acid overnight, rinsed with water and dried before use. Milli-Q water (Millipore, Bedford MA, USA) was used throughout this study, and all other chemicals used were of analytical reagent grade, unless otherwise stated.

\section{Instrumentation}

A double-channel intermittent-flow vapor-generation nondispersive atomic fluorescence spectrometer (VG-NDAFS) (AFS2202a; Beijing Vital Instrument Co., China) was used, in

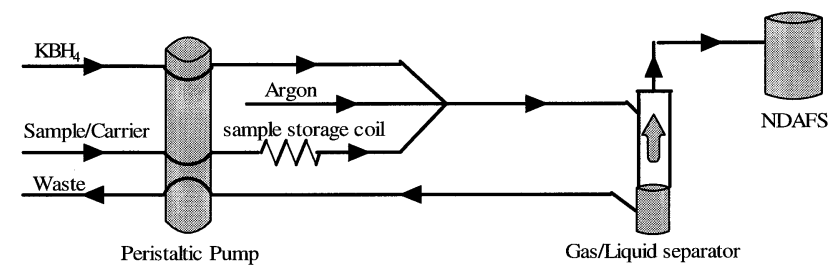

Fig. 1 Schematic diagram of VG-NDAFS.

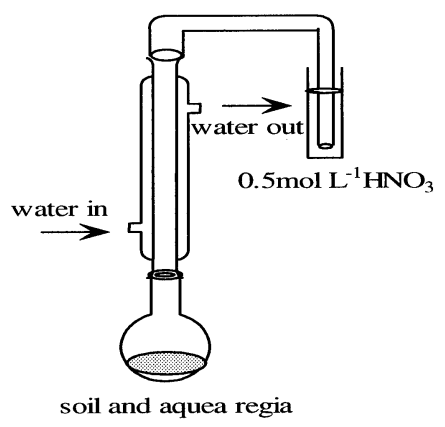

Fig. 2 Digestion apparatus for soil sample.

which coded hollow cathode lamps (HCL; Beijing Institute of Vacuum Electronics Research, China) of As (193.7 nm), Cd (228.8 nm), $\mathrm{Pb}(283.3 \mathrm{~nm})$ and $\mathrm{Hg}(253.7 \mathrm{~nm})$ were used as excitation-light sources, and a photomultiplier tube (PMT; Hamamatsu, Japan) only responding to light shorter than 350 $\mathrm{nm}$ was equipped. No light-dispersion device was used in this system. A schematic diagram and the experimental conditions of VG-NDAFS are shown in Fig. 1 and Table 2.

\section{Sample collection and pretreatment}

Soil samples were collected from urban area of Xiamen at a depth of approximately $30 \mathrm{~cm}$. The soil samples were dried at $105^{\circ} \mathrm{C}$, grounded to pass through a 200 mesh sieve and transferred to polyethylene bottles. The apparatus used for the digestion of soil samples is shown in Fig. 2. Appropriate amounts of soil samples were taken in a $100-\mathrm{mL}$ flask containing an appropriate amount of aqua regia at room temperature over night to allow slow oxidation of the organic matter in the soil samples, and then heated slowly to keep the condensation zone lower than $1 / 3$ of the height of the condenser for $2 \mathrm{~h}$ (Fig. 2). Finally, the residual solutions in the flask and in the absorption tube $\left(15 \mathrm{~mL}\right.$ of $\left.0.5 \mathrm{~mol} \mathrm{~L}^{-1} \mathrm{HNO}_{3}\right)$ were combined together, filtered and transferred to a $100-\mathrm{mL}$ volumetric flask for further determination.

The airborne particulate matters (PMs) were collected at a flow rate of $120 \mathrm{~L} \mathrm{~min}^{-1}$ for $24 \mathrm{~h}$ using a high-volume sampler. Half of the membrane filter was put into a double-layer Teflon digestion bomb, which contained 0.5-2 $\mathrm{mL}$ of high purity concentrated $\mathrm{HNO}_{3}$ in the outer layer. After $4 \mathrm{~h}$ of digestion at $140^{\circ} \mathrm{C}$, the residue in the inner vessel was diluted with $2 \%(\mathrm{v} / \mathrm{v})$ $\mathrm{HNO}_{3}$, filtered with $0.45 \mu \mathrm{m}$ membrane filter, and finally diluted to $10 \mathrm{~mL}$ for VG-NDAFS determination. The blank of the membrane filter was also determined at the same time.

Seawater was colleted and filtered with a $0.45 \mu \mathrm{m}$ membrane filter. Then, $5.0 \mathrm{~mL}$ of seawater was added into a $10 \mathrm{~mL}$ volumetric flask containing $2 \mathrm{~mL}$ of $5 \%$ thiourea, $2 \mathrm{~mL}$ of $5 \%$ ascorbic acid and $0.2 \mathrm{~mL}$ of $\mathrm{HCl}$, diluted to $10 \mathrm{~mL}$ with Milli-Q water for the determination of arsenic. In the determination of cadmium and lead, $2 \mathrm{~mL}$ of concentrated $\mathrm{HNO}_{3}$ was added into 
Table 3 Analytical results for hazardous heavy metals in CRM GSD-8, soil, airborne particulates and seawater collected around Xiamen in China ${ }^{\mathrm{a}}$

\begin{tabular}{|c|c|c|c|c|c|c|c|c|c|c|c|c|}
\hline & \multicolumn{4}{|c|}{ Certified value $/ \mu \mathrm{g} \mathrm{g}^{-1}$} & \multicolumn{4}{|c|}{ Found/ $\mu \mathrm{g} \mathrm{g}^{-1}$} & \multicolumn{4}{|c|}{ Recovery, $\%^{\mathrm{e}}$} \\
\hline & As & $\mathrm{Cd}$ & $\mathrm{Pb}$ & $\mathrm{Hg}$ & As & $\mathrm{Cd}$ & $\mathrm{Pb}$ & $\mathrm{Hg}$ & As & $\mathrm{Cd}$ & $\mathrm{Pb}$ & $\mathrm{Hg}$ \\
\hline GSD-8 & $2.4 \pm 0.6$ & $0.081 \pm 0.017$ & $21 \pm 4$ & $0.042 \pm 0.005$ & $2.1 \pm 0.1$ & $0.072 \pm 0.004$ & $19 \pm 1$ & $0.040 \pm 0.002$ & & & & \\
\hline Soil-1 & & & & & $3.2 \pm 0.2$ & $5.7 \pm 0.4$ & $14.8 \pm 0.3$ & $0.6 \pm 0.05$ & 93.6 & 92.0 & 90.8 & 104.7 \\
\hline Soil-2 & & & & & $2.7 \pm 0.3$ & $4.3 \pm 0.2$ & $15.3 \pm 0.2$ & $3.6 \pm 0.2$ & 95.1 & 91.0 & 88.7 & 92.6 \\
\hline Soil-3 & & & & & $4.4 \pm 0.3$ & $4.8 \pm 0.2$ & $12.0 \pm 0.5$ & $1.7 \pm 0.09$ & 102.5 & 96.4 & 94.3 & 89.3 \\
\hline $\mathrm{PMs}^{\mathrm{b}}$ & & & & & $2.15 \pm 0.03$ & $5.9 \pm 0.07$ & $15.4 \pm 0.6$ & n.d. & 90.3 & 96.7 & 89.7 & 92.0 \\
\hline S.W. $-1^{\mathrm{c}}$ & & & & & $2.8 \pm 0.09$ & $0.84 \pm 0.03$ & $1.36 \pm 0.06$ & $0.03 \pm 0.002$ & 95.0 & 102.6 & 96.1 & 96.0 \\
\hline S.W. $-2^{c}$ & & & & & $2.1 \pm 0.08$ & $1.1 \pm 0.07$ & $1.82 \pm 0.05$ & $0.05 \pm 0.003$ & 89.0 & 98.5 & 104.0 & 90.3 \\
\hline S.W. $-3^{\mathrm{c}}$ & & & & & $3.2 \pm 0.06$ & $0.52 \pm 0.02$ & $2.06 \pm 0.08$ & $0.02 \pm 0.001$ & 97.2 & 98.6 & 95.7 & 102.0 \\
\hline
\end{tabular}

a. Average value of 3 times experiments. b. $\mathrm{ng} \mathrm{m}^{-3}$. c. $\mathrm{ng} \mathrm{mL}^{-1}$. d. Not detected. e. Spiked amount of As, $\mathrm{Cd}, \mathrm{Pb}$ and $\mathrm{Hg}$ was $5 \mu \mathrm{g}$ each for soil samples, $50 \mathrm{ng}$ each for airborne particulates, and $50 \mathrm{ng}$ each for seawater.

$20.0 \mathrm{~mL}$ of seawater, and then the solution was heated slowly to almost dryness, and finally diluted to $10 \mathrm{~mL}$ with $2 \%$ (v/v) $\mathrm{HCl}$ In the determination of mercury, $0.2 \mathrm{~mL}$ of $\mathrm{HCl}$ and $2 \mathrm{~mL}$ of 0.1 mol L-1 $\mathrm{KBr}^{-\mathrm{KBrO}_{3}}$ were added to $5.0 \mathrm{~mL}$ of seawater for the decomposition of organic mercury, and then $0.2 \mathrm{~mL}$ of $30 \%$ (w/v) $\mathrm{NH}_{2} \mathrm{OH} \cdot \mathrm{HCl}$ was added to react with the extra bromine. Finally, the residual solution was diluted to $10 \mathrm{~mL}$ with Milli-Q water.

\section{Results and Discussion}

Vapor generation of hazardous heavy metals

Potassium tetrahydroborate was used as a reductant for generating volatile species of hazardous heavy metals in this study. During the process of volatile species generation, both the acidity and the amount of $\mathrm{KBH}_{4}$ were very important for the efficiency of volatile species generation. The optimum experimental conditions are listed in Table 2. It was found that the acidity in the medium for lead vapor generation should be controlled at $\mathrm{pH} 8-9$, besides the addition of $2 \% \mathrm{~K}_{3} \mathrm{Fe}(\mathrm{CN})_{6}$ for oxidizing $\mathrm{Pb}^{\mathrm{II}}$ to $\mathrm{Pb}^{\mathrm{IV}}$, where $0.5 \%$ tartaric acid was used as a masking reagent for eliminating any interference from coexisting transitional metal ions, such as $\mathrm{Fe}^{3+}, \mathrm{Co}^{2+}, \mathrm{Ni}^{2+}$ and $\mathrm{Cu}^{2+}$. When $\mathrm{As}, \mathrm{Cd}$ and $\mathrm{Hg}$ were determined, $5 \%$ thiourea and $5 \%$ ascorbic acid were used for similar purposes.

\section{Performance of VG-NDAFS}

Argon was used not only as the carrier gas for introducing the generated volatile species of the analytes into the atomizer, but also as a shielding gas of the pure $\mathrm{Ar}-\mathrm{H}_{2}$ flame to get rid of any interference from air, in which $\mathrm{H}_{2}$ was generated from the vapor generation reaction, and then no additional $\mathrm{H}_{2}$ supply was needed. Under the optimum conditions given in Table 2, the detection limit (DL) $(3 \sigma)$ was $0.08 \mathrm{ng} \mathrm{mL}^{-1}$ for As, $0.03 \mathrm{ng}$ $\mathrm{mL}^{-1}$ for $\mathrm{Cd}, 0.05 \mathrm{ng} \mathrm{mL} \mathrm{m}^{-1}$ for $\mathrm{Pb}$ and $0.01 \mathrm{ng} \mathrm{mL} \mathrm{m}^{-1}$ for $\mathrm{Hg}$, respectively. The relative standard deviation (RSD) at $10 \mathrm{ng}$ $\mathrm{mL}^{-1}$ each for $\mathrm{As}, \mathrm{Cd}, \mathrm{Pb}$ and $\mathrm{Hg}$ was $0.9,1.6,1.3$ and $2 \%$, respectively. Such a good performance of VG-NDAFS is comparable to those of GF-AAS and conventional quadrupole ICP-MS, besides the advantages of less spectral interference.

\section{Sample analysis}

During digestion of the soil samples in the sample digestion apparatus, shown in Fig. 2, most of the analytes were cooled by recycling water and returned to the flask. However, since some volatile species were carried out of the condenser, an absorption trap with $0.5 \mathrm{~mol} \mathrm{~L}^{-1} \mathrm{HNO}_{3}$ was used to suppress the losses of analytes, especially for mercury, during the digestion of soil samples. The analytical results for $\mathrm{As}, \mathrm{Cd}, \mathrm{Pb}$ and $\mathrm{Hg}$ in certified reference material GSD-8 (CRM, Ministry of Geology, China), the soils, airborne particulates and seawater are listed in Table 3. The analytical values for $\mathrm{As}, \mathrm{Cd}, \mathrm{Pb}$ and $\mathrm{Hg}$ in GSD-8 were in good agreement with the certified values, and the recoveries of analytes were in the range from 88.7 to $105 \%$. The concentrations of hazardous heavy metals in Xiamen area were from $0.02 \pm 0.001 \mathrm{ng} \mathrm{mL}^{-1}$ in seawater to $15.3 \pm 0.2 \mu \mathrm{g} \mathrm{g}^{-1}$ in soils. They were much lower than the regulated values for "suitable to live" according to National Environment Quality Standard for Soils GB15618-1995, National Ambient Air Quality Standard GB3095-1996 and National Sea Water Quality GB3097-1997 of China. Xiamen is an island with few heavy industries. With the help of sea breeze and seawater, the city has the ability to "self-clean". The results for hazardous heavy metals in the environmental samples obtained by VG-NDAFS support that there is little pollution caused by hazardous heavy metals in the Xiamen area.

\section{Conclusion}

Compared to the expensive working cost and complex instrumentation systems of GF-AAS and ICP-MS, it was found from the present research that VG-NDAFS could be another powerful tool for the determination of arsenic, cadmium, lead and mercury in the environment. According to the concentrations of hazardous heavy metals in environmental samples evaluated by VG-NDAFS, Xiamen is still a clean city in China.

\section{Acknowledgements}

The authors thank the loan of the AFS-2202a atomic fluorescence spectrometry from Beijing Vital Instrument Company. This study was financially supported partly by NSFC (No. 20175019) and Doctoral Research Foundation of Education Ministry of China (No. 20020384003).

\section{References}

1. W. M. Stigliani and P. Deolman, Environment, 1991, 33, 4. 2. M. Tüzen, Microchem. J., 2003, 74, 289. 
3. J. Komárek and J. Holý, Spectrochim. Acta Part B, 1999, $54,733$.

4. S. Tokalioglu, S. Kartal, and L. Elçi, Anal. Chim. Acta, 2000, 413, 33.

5. S. Saracoglu, M. Soylak, and L. Elçi, Talanta, 2002, 59, 287.

6. M. Bettinelli, G. M. Beone, S. Spezia, and C. Baffi, Anal. Chim. Acta, 2000, 2, 289.

7. J. Goossens, L. Moens, and R. Dams, Anal. Chim. Acta, 1995, 304, 307.

8. V. L. Dressler, D. Pozebon, and A. J. Curtius, Spectrochim Acta Part B, 1998, 53, 1527.

9. G. Tao, R. Yamada, Y. Fujikawa, A. Kudo, J. Zheng, D. A. Fisher, and R. M. Koerner, Talanta, 2001, 55, 765.

10. F. A. M. Planchon, C. F. Boutron, C. Barbante, and E. W. Wolff, Anal. Chim. Acta, 2001, 450, 193.

11. J. Li, F. Lu, T. Umemura, and K. Tsunoda, Anal. Chim. Acta, 2000, 419, 65

12. H. Lu, S. Mou, and J. M. Riviello, J. Chromatogr. A, 1999, $857,343$.

13. A. Shawi, W. Abdulla, and R. Dahl, Anal. Chim. Acta,
1999, 391, 35.

14. M. Sikovec, M. Novic, and M. Franko, J. Chromatogr. A, 1996, 739, 111.

15. L. Wei, P. Gupta, R. Hernandez, and F. Farhat, Microchem. J., 1999, 62, 83.

16. H. Morita, H. Tanaka, and S. Shimomura, Spectrochim. Acta Part B, 1995, 50, 69.

17. Stanley Greenfield, Tre. Anal. Chem., 1995, 15, 435.

18. K. C. Thompson and D. R. Thomerson, Analyst, 1974, 99, 595.

19. K. C. Thompson and G. D. Reynolds, Analyst, 1971, 96, 771

20. X. W. Guo and X. M. Guo, Anal. Chim. Acta, 1995, 310, 377.

21. H. G. Infante, M. L. F. Sanchez, and A. Sanz Medel, J. Anal. At. Spectrom., 1996, 11, 571.

22. R. E. Sturgeon and Z. Mester, Appl. Spectrom., 2002, 56, 202.

23. Z. Jiang, L. Tian, X. Chen, B. Hu, and Y. Feng, "Modern Atomic Emission Spectrometry", 1999, Science Press, Beijing, 68 